\title{
Recent observations of seasonal variability of the Mediterranean outflow in the Strait of Gibraltar
}

\author{
J. García Lafuente, ${ }^{1}$ A. Sánchez Román, ${ }^{1}$ G. Díaz del Río, ${ }^{2}$ G. Sannino, ${ }^{3}$ \\ and J. C. Sánchez Garrido ${ }^{1,4}$ \\ Received 26 October 2006; revised 15 February 2007; accepted 13 June 2007; published 4 October 2007.
}

[1] Recent observations of the outflowing Mediterranean water collected near the bottom in key points of the Strait of Gibraltar show the existence of a seasonal cycle with warmer and lighter waters leaving the Mediterranean Sea in winter and cooler and denser waters in spring early summer. The amplitude of the signal is around $510^{-2}{ }^{\circ} \mathrm{C}$ for potential temperature and $1.510^{-2}$ for potential density, salinity hardly showing seasonal fluctuations. The outflow also shows a seasonal cycle with maximum volume transport in April, in coincidence with the minimum of the signal of potential temperature. A simple analysis of the composition of the outflow in terms of the main water masses of the western Mediterranean basin and its comparison with climate indicators suggests that the seasonal cycle follows the annual process of the Western Mediterranean Deep Water formation that replenish the deep portion of the basin by the end of winter and rises the level of the deep water reservoir, facilitating the suction of cooler and denser water from the Mediterranean over the sills of the Strait. From this time onwards, the data show a smooth warming that would be explained by the progressive fall of the level of the Western Mediterranean Deep Water as it is drained out the Mediterranean, which would leave warmer water available for suction. The process is asymmetric in the sense that the transition from high to low temperature is completed in a short period while the progressive warming spans a longer period.

Citation: García Lafuente, J., A. Sánchez Román, G. Díaz del Río, G. Sannino, and J. C. Sánchez Garrido (2007), Recent observations of seasonal variability of the Mediterranean outflow in the Strait of Gibraltar, J. Geophys. Res., 112, C10005, doi:10.1029/ 2006JC003992.

\section{Introduction}

[2] The Strait of Gibraltar, connecting the Atlantic Ocean with the Mediterranean Sea through a system of sills and narrows, is the scenario of a well-studied baroclinic exchange driven by the net evaporative losses in the Mediterranean Sea [Lacombe and Richez, 1982; Bryden and Kinder, 1991; Bryden et al., 1994; García Lafuente et al., 2000]. A long term barotropic flow $Q_{0}$ of the order of 0.05 $\mathrm{Sv}$ (Sverdrup, $1 \mathrm{~Sv}=10^{6} \mathrm{~m}^{3} \mathrm{~s}^{-1}$ ), which is achieved as the difference of an inflow $Q_{1}$ and an outflow $Q_{2}$ one order of magnitude greater, is necessary to compensate for the evaporation in the Mediterranean. All these flows fluctuate at different timescales, the most important of which is the semidiurnal one. Other less important but non-negligible source of variability is the meteorological forcing that

\footnotetext{
${ }^{1}$ Grupo de Oceanografía Física, University of Málaga, Málaga, Spain.

${ }^{2}$ Laboratorio Oceanográfico de A Coruña, Instituto Español de Oceanografía, A Coruña, Spain.

${ }^{3}$ Ocean Modeling Unit-Special Project Global Climate-ENEA, C.R. Casaccia, Rome, Italy.

${ }^{4}$ Grupo de Puertos y Costas, University of Granada, Granada, Spain.

Copyright 2007 by the American Geophysical Union. 0148-0227/07/2006JC003992\$09.00
}

induces fluctuations in the range of few days of period [Candela et al., 1989; García Lafuente et al., 2002b] and the seasonal and interannual variations. This paper focuses on the seasonal variations of the outflow of the Mediterranean water by analyzing recent observations collected in key points of the Strait of Gibraltar.

[3] The outflowing Mediterranean water is a mixture of intermediate and deep waters residing in the Mediterranean Sea, basically Levantine Intermediate Water (LIW) formed in the eastern Mediterranean basin, which flows across the Strait of Sicily into the western basin, and the Western Mediterranean Deep Water (WMDW) formed in the Gulf of Lions in the western Mediterranean, which occupies the bottom layer. Although the LIW is thought to contribute the bulk of the outflow, there has been historical interest to elucidate the question of whether or not WMDW might be uplifted and flow directly over the 300-m-depth sill of Camarinal (CS hereinafter, see Figure 1), a question of obvious practical importance regarding the renewal of abyssal waters. Stommel et al. [1973] argued that Bernoulli suction in the sill was able to uplift water from about 700 to $1000 \mathrm{~m}$ depth and participate directly in the outflow, a reasoning also supported by laboratory [Whitehead, 1985] and numerical experiments (Figure 2, see next section). Some years later, Kinder and Parrilla [1987] presented 


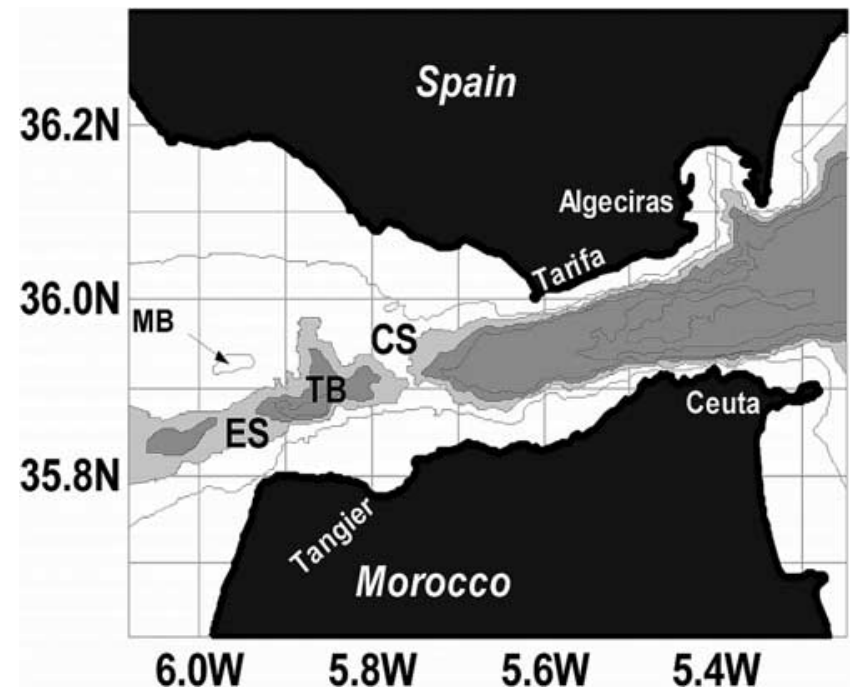

Figure 1. Map of the Strait of Gibraltar showing the main topographic features. CS and ES indicates the location of the sills of Camarinal and Espartel, respectively. The submarine ridge of Majuan Bank (MB) located north of ES and the Tangier Basin (TB) between both sills are also indicated. The plotted isobaths are $100 \mathrm{~m}, 290 \mathrm{~m}$, which is the light shaded contour specifically chosen to highlight the main sill of Camarinal (297 m), $400 \mathrm{~m}$ (the medium-dashed contour), and $500 \mathrm{~m}, 700 \mathrm{~m}$ and $900 \mathrm{~m}$, which are not labeled to keep the map clear.

evidences of WMDW (identified as water with potential temperature below $12.90^{\circ} \mathrm{C}$ ) to the Atlantic side of $\mathrm{CS}$, confirming the hypothesis of Stommel et al. [1973]. The repeated finding of water cooler than below $12.90^{\circ} \mathrm{C}$ west of the sill during surveys carried out in the middle 80 s led Kinder and Bryden [1990] to suggest that the WMDW is outflowing directly on nearly every semidiurnal tidal cycle regardless of the spring-neap cycle and of the time of the year. Since then, properties of the Mediterranean outflow appear to have changed. Recently Millot et al. [2006] have shown that WMDW with the distinctive characteristics it had in the last decades of the last century was not flowing out in years 2003 and 2004. According to these authors, the densest Mediterranean water overflowing CS near the seafloor these years had recognizable characteristics of Tyrrhenian Dense Water (TDW), a water formed when the Eastern Overflow Water from the Eastern Mediterranean cascades from the depth of the Strait of Sicily sill down to near $2000 \mathrm{~m}$ and mixes with old resident WMDW in the Tyrrhenian Sea (Millot, 1999). They concluded that TDW has been progressively replacing WMDW in the outflow through the Strait of Gibraltar. A likely explanation for this replacement is that TDW in the western Mediterranean occupies a layer of variable thickness between LIW and WMDW, the latter being found deeper than some decades ago.

[4] Even if the long-term properties of the outflow had remained unchanged, the former assertion about the systematic suction of WMDW on nearly every tidal cycle is arguable. The late winter deep convection processes that take place in the Gulf of Lions every year replenish the western Mediterranean reservoir with newly formed WMDW and rises the interface between WMDW and the waters above, whatsoever they are. The subsequent partial draining of the reservoir during the rest of the year when the WMDW is not being formed lowers the interface gradually, producing a saw-tooth pattern of the interface height, as discussed by Bormans et al. [1986]. Under these circumstances, the



Figure 2. Percentage of particles that crossed Camarinal sill within 4 days after they were released at uniformly distributed depths (from $230 \mathrm{~m}$ to the seafloor) in the section running along $5^{\circ} 12^{\prime} \mathrm{W}$ (insert in the upper left corner) in the Mediterranean Sea. The experiment is based on the numerical results of the Gibraltar Strait model by Sannino et al. [2004]. A total of 25,479 particles uniformly distributed with $z$ were tracked and only those particles crossing the sill in a bottom-layer $60 \mathrm{~m}$ thick have been counted in the graph. The highest percentage corresponds to particles initially released at $730-780 \mathrm{~m}$, although particles from the whole range of depths do cross the sill. 
signal of WMDW in CS area is expected to be more conspicuous in spring when it is shallower in the Alborán basin and to be less clear or, even, to vanish out in the successive months as the WMDW level drops. The hydrological properties of the outflow will exhibit similar seasonal variability.

[5] The expected seasonal fluctuations of the exchanged flows have been reported using different approaches. The most reliable source is in situ observations, although flows computed from observed currents must be considered cautiously due to the inherent difficulties of the volume transport computations, which arise from the necessity of determining the time-varying location of the interface as well as of extrapolating measurements collected at single points to the whole cross-section. Bryden et al. [1994], using data from CS in years 1985-86, gave annual signals of $0.14 \mathrm{~Sv}$ and $0.03 \mathrm{~Sv}$ amplitude with maximum absolute values in September and January for the inflow and outflow, respectively. The length of the series from which these numbers were deduced is less than a year and, as authors indicate, their estimates have great uncertainty. Candela [2001], based on a nearly two-yearlong time series of Acoustic Doppler Current Profiler (ADCP) currents observed in CS from November 1994 to September 1996, gave a seasonal signal of around $0.14 \mathrm{~Sv}$ amplitude for the outflow, attaining its maximum in early spring, and a poorly defined signal for the inflow, the maximum tending to occur in summer. García Lafuente et al. [2002a], using observations collected in the eastern section of the Strait from October 1995 to May 1998, reported annual signals of $0.1 \mathrm{~Sv}$ for the inflow and $0.03 \mathrm{~Sv}$ for the outflow peaking in the late summer and a noticeable semiannual signal for the outflow that, combined with the former, produced maximum outflow in late winter. The numerical model driven by realistic atmospheric forcing of Béranger et al. [2005] provides similar timing for the outflow cycle. The agreement on when the inflow peaks is poorer. Direct observations points at late summer [Bryden et al., 1994; Candela, 2001; García Lafuente et al., 2002a], but other indirect estimates [Bormans et al., 1986] as well as the model by Béranger et al. [2005] suggest maximum inflow in winter. The net flow has a seasonal cycle whose maximum is observed in summer [Bryden et al., 1994; Candela, 2001; García Lafuente et al., 2002a], whose likely origin resides in the fact that the seasonal cycles of inflow and outflow do not cancel each other on monthly time-scales. This seasonal input of mass-excess into the Mediterranean Sea is neither canceled out by the evaporative cycle on monthly basis [García Lafuente et al., 2002a, 2004], giving rise to a seasonal cycle of mass content in the Mediterranean, which adds on to the steric one due to the solar heating, and that has been recently identified by García et al. [2006] using gravity observations (Gravity Recovery And Climate ExperimentGRACE-Mission).

[6] This paper studies the seasonality of the outflow using a two-yearlong recent series of good-quality observations collected in Espartel sill (ES hereinafter), in the western approach of the Strait of Gibraltar (Figure 1). The reasons to monitor the outflow in this sill are explained in the Appendix A. The results of the study are preliminary in the sense that the data analyzed are part of an ongoing time series aimed at monitoring the flows through the Strait on the long term. With two years of observations some issues related to seasonal and short term interannual variability are already accessible and their study makes up the scope of this paper.

\section{Data and Data Processing}

\subsection{Original Data Sets}

[7] Data were collected in ES and CS, the two main sills of the Strait of Gibraltar. The bulk of data comes from the monitoring station in ES at $35^{\circ} 51.7^{\prime} \mathrm{N}, 5^{\circ} 58.6^{\prime} \mathrm{W}$, equipped with an uplooking moored ADCP at $20 \mathrm{~m}$ above seafloor and a currentmeter (RCM9 from Aanderaa) and an autonomous Conductivity-Temperature-Depth (CTD) probe at 15 and $10 \mathrm{~m}$ above seafloor, respectively. The ES was installed in September 2004 and it is still acquiring information, although this paper analyses the observations collected until September 2006 From February to May 2006 a second mooring line with the same configuration as the ES line was deployed in $\mathrm{CS}$ at $35^{\circ} 54.8^{\prime} \mathrm{N}, 5^{\circ} 44.7^{\prime} \mathrm{W}$ with the aim of comparing simultaneous observations at both sills in order to elucidate whether or not the low frequency signals are equally well monitored in either site (see Appendix A).

[8] The sampling interval of all instruments was 30 min. The vertical bin-size of the ADCP installed in ES was $8 \mathrm{~m}$ and the number of resolved bins was 40 . Only the upper 30 or $40 \mathrm{~m}$ of the water column were missed, although the data quality in the uppermost resolved bins is not good. The information recorded in the bins inside the vein of the Mediterranean outflow, whose interface in ES is about 180 to $200 \mathrm{~m}$ depth, is of good quality. The measurements of the secondary currentmeter below the ADCP were used as the deepest bin of the ADCP in order to compute the total outflow. In situ temperature recorded by the CTD probes was converted to potential temperature $(\theta)$.

\subsection{Climatic Data}

[9] The variance adjusted version of the air temperature anomalies on a $5^{\circ} \times 5^{\circ}$ grid of the Climate Research Unit of the University of East Anglia (CRUTEM3v data set, see http:/www.cru.uea.ac.uk) has been used as a proxy for climatological conditions. The CRUTEM $3 \mathrm{v}$ data set is computed by reducing monthly average temperatures to anomalies from the period with best coverage (1961-90) in order to avoid biases that arise from the fact that different countries estimate average monthly temperatures using different methods and formulae [see Rayner et al., 2003, 2006; Brohan et al., 2006 for details]. Anomalies in the cells covering the Gulf of Lions have been averaged to provide a representative value in the area. The winter interannual variability of these anomalies are assumed to be related to the interannual variability of the western Mediterranean deep convection processes, a fact that will be invoked later in order to interpret the low frequency variability of the hydrological data set.

\subsection{Particle Trajectories}

[10] The numerical model of the exchange through the Strait of Gibraltar developed by Sannino et al. [2004] has been used to produce virtual trajectories of particles in order to find out the depths from which dense Mediterranean water parcels can be uplifted and suctioned out over CS. 

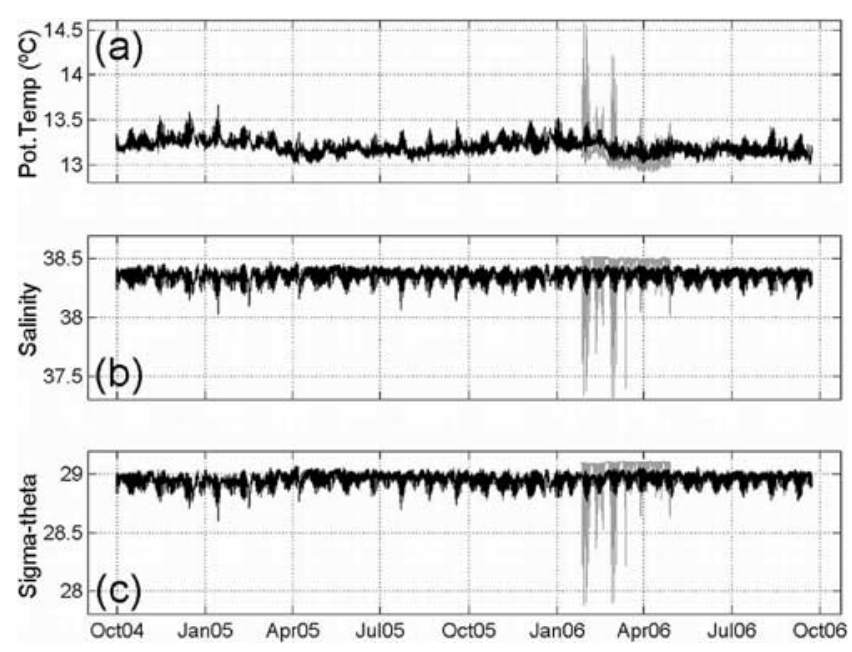

Figure 3. (a) Time series of potential temperature, (b) salinity and, (c) sigma-theta recorded at around $10 \mathrm{~m}$ above the seafloor in ES (black line) and CS (grey line).

Details of the model can be found in the works of Sannino et al. [2002, 2004]. Trajectories have been simulated offline with a three dimensional second-order Runge-Kutta scheme that takes into account both advection and diffusion. The position of each particle in the 3-D space is estimated in two steps through the following expressions:

$$
\begin{aligned}
x_{n+1 / 2} & =x_{n}+\mathbf{v}_{n}\left(x_{n}\right) \Delta t / 2, \\
x_{n+1} & =x_{n}+\mathbf{v}_{n+1 / 2}\left(x_{n+1 / 2}\right) \Delta t+\mathbf{w}_{n}
\end{aligned}
$$

where $x_{n}$ is the initial position of the particle at time $n \Delta t$, $x_{n+1 / 2}$ is the intermediate position at time $n \Delta t+\Delta t / 2$ due to the advective component of velocity $\mathbf{v}_{n}\left(x_{n}\right)$ (derived at time $n \Delta t$ from the $20 \mathrm{~min}$ mean velocity field of the hydrodynamic model) and $x_{n+1}$ is the final estimated position of the particle at time $(n+1) \Delta t$ that takes into account the diffusion of velocity $\mathbf{w}_{n}$ mimed through a random walk scheme:

$$
\left\{\begin{array}{l}
\mathrm{w}_{n}^{x}=\gamma_{n}^{x} \sqrt{\left(2 A m_{n} \Delta t\right)} \\
\mathrm{w}_{n}^{y}=\gamma_{n}^{y} \sqrt{\left(2 A m_{n} \Delta t\right)} \\
\mathrm{w}_{n}^{z}=\gamma_{n}^{z} \sqrt{\left(2 K m_{n} \Delta t\right)}
\end{array}\right.
$$

In these expressions, $\gamma_{n}^{x}, \gamma_{n}^{y}$ and $\gamma_{n}^{z}$ are random numbers distributed normally with zero mean and unit standard deviation, and $A m_{n}$ and $K m_{n}$ are the horizontal and vertical diffusion coefficients, respectively, at time $n \Delta t$ computed by the hydrodynamic model. A time step $\Delta t=60 \mathrm{~s}$ has been used in order to satisfy the Courant-Friedrich-Lewy stability criterion. Figure 2 shows the statistic of the particles realized in a section east of the Strait that crossed CS in a layer attached to the bottom $60 \mathrm{~m}$ thick.

\subsection{Mediterranean Water Time Series}

[11] The denomination Mediterranean water henceforth refers to the intermediate and deep water masses formed inside the Mediterranean Sea that are observed in the Strait. It includes LIW, WMDW and other water masses as the recently detected TDW [Millot et al., 2006]. The observa- tions of the Mediterranean water are largely affected by tides at semidiurnal and fortnightly frequencies, the range of tidal fluctuations being higher in CS where all variables show lower minima and higher maxima than in ES (Figure 3). It is a consequence of the strong mixing with the overlying Atlantic water associated with the internal hydraulic jump and other undulatory features that form and evolve downstream of CS, in the Tangier basin [Wesson and Gregg, 1994; Bruno et al., 2002]. Mixing not only smoothes out tidal fluctuations but also erodes the $\theta / \mathrm{S}$ signatures of the Mediterranean water.

[12] To investigate low frequency variability it is convenient to remove these tidal fluctuations. Numerical filters are not appropriate to this aim because they stress the effect of mixing by smoothing the $\theta / \mathrm{S}$ characteristics of the lessmixed Mediterranean water we are interested in. Instead of filtering, the time series were divided into pieces of one semidiurnal tidal cycle and the absolute minimum of $\theta$, and maxima of $S$ and $\sigma_{\theta}$ of each piece were identified. The result is nearly tidal-free series (fortnightly signal is still recognizable) at nearly regular intervals of the, supposedly, lessmixed Mediterranean water overflowing the sills (Figure 4). The series of extremes show less variability in CS than in ES. Here, $\theta_{\min }$ and $S_{\max }$ are higher and lower, respectively, than in CS due to the mixing with the overlying North Atlantic Central Water (NACW) in the Tangier basin that erodes the $\theta / \mathrm{S}$ signature of the Mediterranean outflow. Figure 4 shows more regular low frequency variability in $\theta_{\min }$ and in $\sigma_{\theta \text { max }}$ than in $S_{\max }$. On the other hand, the low frequency signal of $\sigma_{\theta, \max }$ is achieved through the corresponding signal in $\theta_{\text {min }}$, as demonstrated by the fact that $\theta_{\min }$ and $\sigma_{\theta, \max }$ occurred simultaneously in two out of three tidal cycles and they occurred within $\pm 1 \mathrm{~h}$ in more than $90 \%$ of them. For these reasons, most of our analysis will focus on the potential temperature and density records.

[13] One question that arises is whether or not the subsampled series obtained by choosing up the extremes of


Figure 4. (a) Series of $\theta_{\min }$ found in each semidiurnal tidal cycle. (b) Same as in (a) for $S_{\max }$. (c) Same as in (a) for $\sigma_{\theta \text {,max }}$. Black lines are for ES and grey lines are for CS. Black thick lines are the fitting of the observations to the model of equation (1). 
Table 1. Results of Fitting the Different Series of Extremes in Espartel Sill to the Annual and Semiannual Model of Equation (1) and the $95 \%$ Confidence Interval for Each Parameter

\begin{tabular}{|c|c|c|c|c|c|c|c|}
\hline & \multirow[b]{2}{*}{$y_{0}$} & \multirow[b]{2}{*}{$b^{\mathrm{a}}$} & \multicolumn{2}{|c|}{ Annual } & \multicolumn{2}{|c|}{ Semiannual } & \multirow[b]{2}{*}{$r^{2}$} \\
\hline & & & $A_{a} \times 10^{2}$ & $\varphi_{a}, \operatorname{deg}$ & $A_{a} \times 10^{2}$ & $\varphi_{a}, \operatorname{deg}$ & \\
\hline$\theta_{\min }\left({ }^{\circ} \mathrm{C}\right)$ & $13.145 \pm 0.012$ & - & $4.92 \pm 0.38$ & $345 \pm 5$ & $3.03 \pm 0.30$ & $0 \pm 6$ & 0.60 \\
\hline$S_{\max }$ & $38.408 \pm 0.007$ & $(-)$ & $0.63 \pm 0.27$ & $144 \pm 25$ & $0.58 \pm 0.26$ & $213 \pm 26$ & 0.08 \\
\hline$\sigma_{\theta, \max }$ & $29.005 \pm 0.007$ & + & $1.42 \pm 0.25$ & $158 \pm 10$ & $1.01 \pm 0.22$ & $193 \pm 13$ & 0.24 \\
\hline $\mathrm{Q}_{2}(\mathrm{~Sv})$ & $-0.85 \pm 0.03$ & + & $4.9 \pm 0.3$ & $267 \pm 9$ & $3.0 \pm 0.9$ & $19 \pm 18$ & 0.59 \\
\hline
\end{tabular}

${ }^{a}$ Column 'b' shows the sign of the trend computed in the fitting, whose meaning is arguable due to the shortness of the series. In the case of Smax, the trend is not-significant at $95 \%$ confidence level. Last column gives the regression coefficient of the fitting. The outflow is a negative quantity so that the phase of the annual and semiannual signals give the time of the less negative outflow, that is, the minimum outflowing volume in magnitude. The phase of the maximum outflowing volume will be shifted by $180^{\circ}$.

each tidal cycle are the most suitable for monitoring the outflow of dense Mediterranean water. The question is addressed in Appendix B, where it is shown that the time corresponding to the densest water sample selected within each tidal cycle coincides with the time of more favorable tidal currents to ensure that the sample is effectively drained out the Mediterranean. This result supports the representativeness of the extreme series of $\sigma_{\theta, \max }$ (and, hence, of $\left.\theta_{\min }\right)$ for the less-mixed Mediterranean water outflow.

\section{Seasonal Signals}

\subsection{Harmonic Analysis}

[14] The time series of Figure 4 have been fitted to the seasonal model

$$
y(t)=y_{0}+b t+A_{a} \cos \left(\omega_{a} t-\varphi_{a}\right)+A_{s} \cos \left(\omega_{s} t-\varphi_{s}\right)
$$

where $y_{0}$ is the mean, $b$ represents a trend, $A_{a}$ and $A_{s}$ are the amplitudes of annual and semiannual signals, respectively, and $\varphi_{a}$ and $\varphi_{s}$ their phases referred to day 0 of the year. With this criterion, the phase of the annual signal expressed in degrees roughly coincides with the day of the year. Table 1 gives the different parameters of the fitting and confirms that the clearest seasonality is found in $\theta_{\min }$ series with warmer water flowing by the end of the year (phase of $345^{\circ}$ ). The semiannual signal, necessary to explain the asymmetry of the seasonal cycle, is significant for $\theta_{\min }$ and $\sigma_{\theta, \max }$ and it flattens the curve between the maxima (Figure 4) making $\theta_{\text {min }}$ drop after reaching the seasonal maximum and then increase slowly toward the next maximum, thus giving a saw-tooth shape to the curve. Salinity hardly has significant seasonal signals (very low values of $r^{2}$ in Table 1 ), while $\sigma_{\theta \text {,max }}$ shows a signal induced by $\theta_{\min }$ and is therefore out of phase with it.

[15] The low-passed time series of the along-strait ADCP velocity in ES (Figure 5a) has been used to compute the outflow (Figure 5b), which has been also fitted to the seasonal model with the results showed in the last row of Table 1. In addition to the enhanced variability driven by the stronger meteorological forcing in winter, the fitted curve indicates more outflow (in magnitude) in spring. The reduced length of the time series, the large meteorologically driven mesoscale variability and the weak amplitude of the computed seasonal signal make us to be cautious, even if the result agrees with previously reported values based on time series of similar or less length [Bryden et al., 1994; Candela, 2001; García Lafuente et al., 2002a]. It is interesting to notice that the time of the year of maximum outflow nearly coincides with the detection of the lowest values of $\theta_{\min }$ (Figure 4; Table 1).

\subsection{Seasonal Variation of Composition of Outflow}

[16] The $\theta / \mathrm{S}$ diagram in Figure 6a shows all observations at ES and CS and suggests two different patterns of mixing. The dashed line would indicate mixing of Mediterranean with the overlying NACW, the source of fresher water. It is mainly forced by tides, spring tides in particular as suggested by the fortnightly pattern of the large fluctuations of temperature and salinity in Figure 3. The double headed arrow of Figure 6a would indicate a second type of mixing between different water masses of Mediterranean origin, but the following analysis suggests that the distribution of $\theta / \mathrm{S}$ points in this part of the diagram is partially determined by the different proportion of the water masses of Mediterranean origin in the outflow through the Strait of Gibraltar along the year.

[17] Figure $6 \mathrm{~b}$ shows the $\theta / \mathrm{S}$ pairs corresponding to the series of $\sigma_{\theta \text {,max }}$ in ES and CS. Three $\theta / \mathrm{S}$ pairs representing LIW, WMDW, and NACW characteristics in the vicinity of the Strait have been selected in the diagram with the aim of investigating seasonal variations in the composition of the less-mixed Mediterranean water flowing out. Their numerical values are $\theta=13.22^{\circ} \mathrm{C}, \mathrm{S}=38.56$ for $\mathrm{LIW}, \theta=$ $12.80^{\circ} \mathrm{C}, \mathrm{S}=38.45$ for $\mathrm{WMDW}$ and $\theta=15.0^{\circ} \mathrm{C}, \mathrm{S}=36.2$

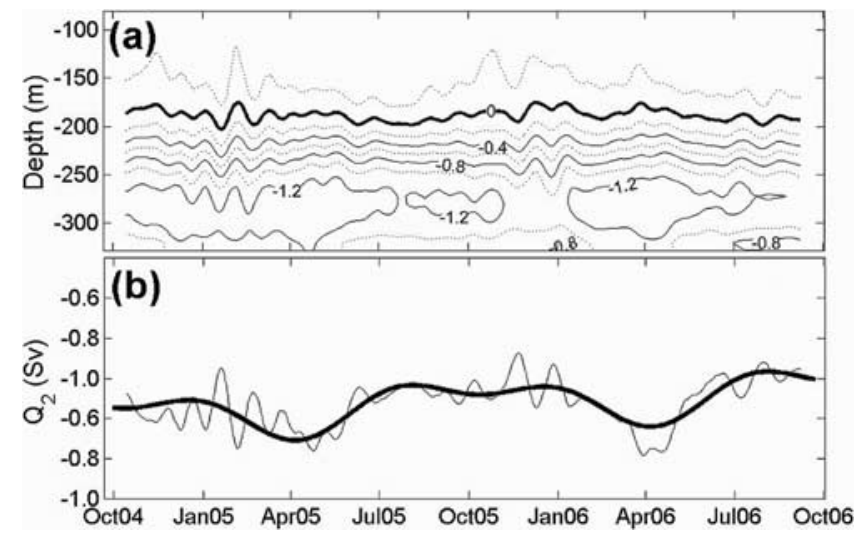

Figure 5. (a) Low-passed time series (15-day cut-off period) of along-strait ADCP velocities in ES. (b) outflow computed from these observations. The outflow does not include the fraction of the Mediterranean water flowing north of Majuan Bank (see Figure 1), which is estimated to be around $10 \%$ of that showed in (b). The thick line is the fitting of the series to the seasonal model. 

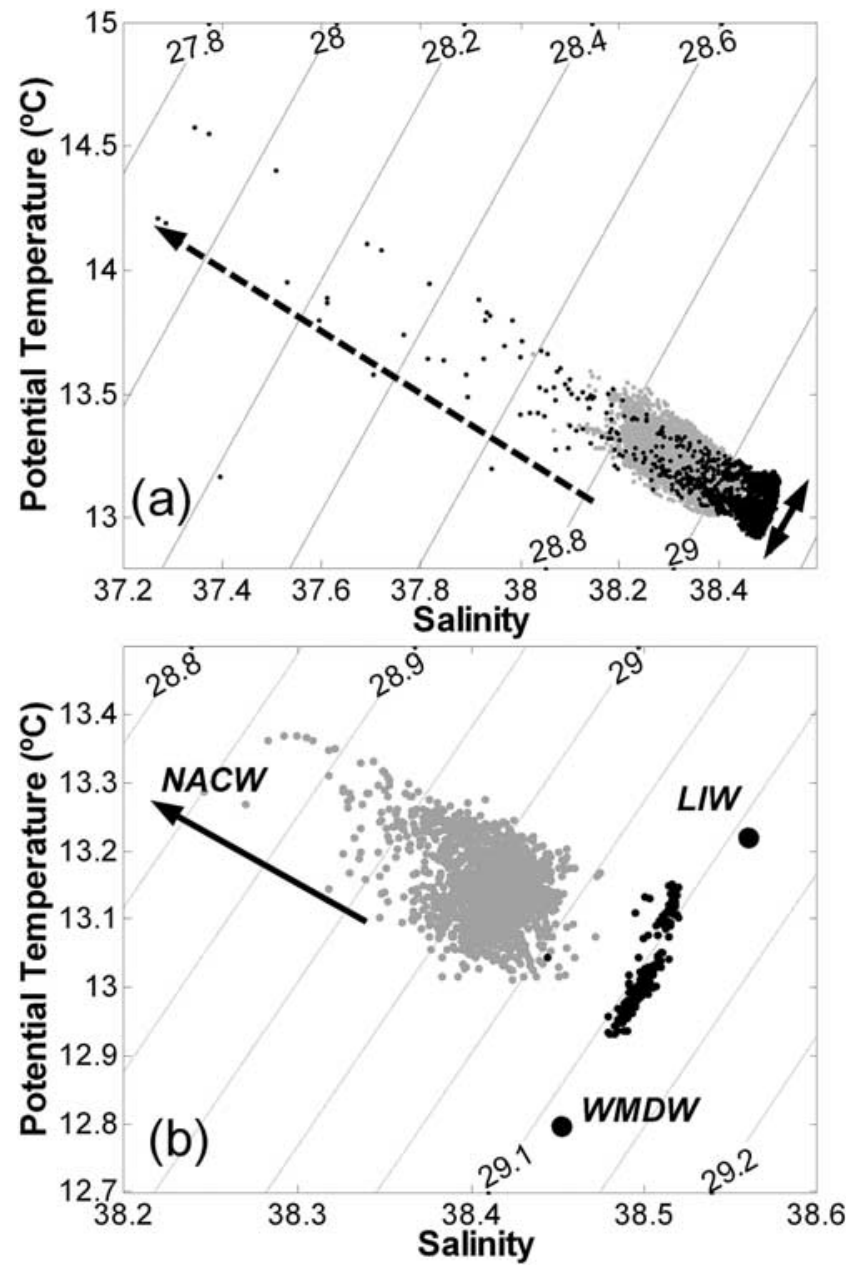

Figure 6. (a) Potential temperature/Salinity diagram of the observations in CS (black dots) and ES (grey dots). (b) Same as (a) showing the pairs corresponding to the series of the densest $\left(\sigma_{\theta, \max }\right)$ samples. Dots labeled WMDW and LIW indicate the $\theta / S$ characteristics used to estimate the proportions of each water mass showed in Figure 7.

for NACW (to the left in Figure 6b). The triangle defined by these apices encircles all $\theta / \mathrm{S}$ pairs. The points are not intended to reflect precisely the hydrological characteristics of LIW and WMDW, which, on the other hand, are spatially variable, but to represent reasonably well their properties in the Alborán Sea (east of the Strait) according to Parrilla et al. [1986] and to the historical data [MEDAR Group, 2002]. The $\theta$ and $S$ values selected to characterize the NACW are harder to justify because NACW is a water mass whose signature in the $\theta / \mathrm{S}$ diagram is a straight line and any other point of this line could have been used instead (obviously the selected point belongs to the empirical line). However, the large distance between the cluster of points in Figure $6 \mathrm{~b}$ and the position of the NACW line makes the coefficients of the water composition computed below be hardly sensitive to the specific point representing the NACW.

[18] The time series of the fraction of those water masses in each sample of Figure $6 \mathrm{~b}$ are shown in Figure 7. According to this decomposition, the near-bottom, lessmixed Mediterranean water in $\mathrm{CS}$ is free of traces of NACW $(0.4 \%$ on average) while it has a non-negligible, though very small, proportion in ES (4.5\%) as a consequence of mixing in the Tangier basin. The smallness of the NACW proportion confirms that the selection of the point representing this water mass is not critical in the decomposition; any other point in the NACW will provide almost identical results. In addition to the noticeable mesoscale variability, the proportion of LIW and WMDW follows a clear seasonal pattern in ES. Although the short series of available data in CS does not permit to extend the conclusion to this sill, the similitude of plots in Figure $7 \mathrm{~b}$ along with the discussion presented in Appendix A (see Figure A1) suggest the same variability in both sills. Thus we conclude that the proportion of WMDW leaving the Mediterranean Sea increased suddenly in March 2005, remained relatively high during summer to decreases to a minimum by the end of the year and the beginning of year 2006. It increased suddenly again by the end of February, 2006 and remained high during summer. LIW behaves like a mirror image due to the almost null influence of NACW.

\section{Discussion and Conclusions}

\subsection{Annual Cycle of $\boldsymbol{\theta}_{\min }$ and Deep Water Formation}

[19] The variations of the proportion of the different water masses is clearly linked to the temporal variability of $\boldsymbol{\theta}_{\min }$ shown in Figure 4a. The coincidence of the maximum annual signal of the outflow and the minimum potential temperature (compare Figures $4 \mathrm{a}$ and $5 \mathrm{~b}$ ) or, equivalently, the appearance of water with greater proportion of WMDW in spring, suggests a common origin for both features, the most obvious reason being the winter formation of WMDW in the Gulf of Lions area [MEDOC Group, 1970; Schott and Leaman, 1991; Send et al., 1995; Testor and Gascard, 2006].

[20] The seasonal composition showed in Figure 7 can be explained by the different type of water lying at the depth from which it can be suctioned out the Mediterranean Sea along the year. The composition analysis indicates a major presence of WMDW shortly after the epoch of the deep convection. This convection replenishes the WMDW reservoir and raises its interface with the water above, making cooler/denser water available for suction. As this water is drained out, it is progressively replaced by the slightly warmer overlying water, a fact reflected by the smooth and progressive warming of the water detected overflowing the sills. The sudden decrease of $\theta$ in the Strait by the end of March 2005 and in March 2006 should be the remote signature of the deep convection in the Gulf of Lions delayed by some days, the time it takes an internal wave to reach the Alboran basin from the Gulf of Lions.

[21] The replenishment of the deep western Mediterranean basin in late winter or early spring with newly formed and denser WMDW increases the density difference between the eastern and western part of the Strait. The outflow, which is proportional to the squared root of the horizontal density gradient [Bryden and Kinder, 1991], will increase during this part of the year as well, in agreement with the observations and with historical references [Bryden et al., 1994; Candela, 2001; García Lafuente et al., 2002a]. This maximum transport of slightly denser water would favor the existence of a concomitant seasonal signal in the properties of the Mediterranean plume in the North Atlantic. 


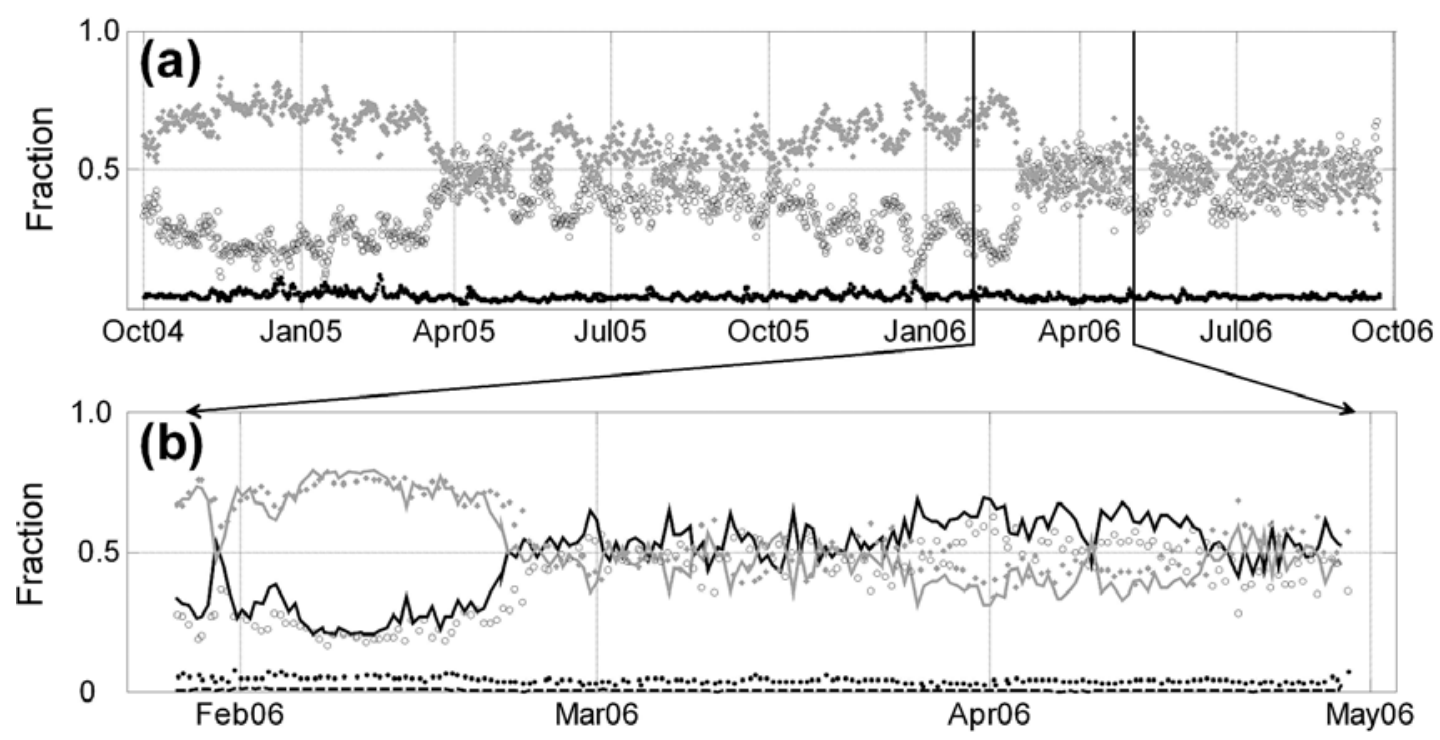

Figure 7. (a) Fraction of the different water masses defined in the text (see also Figure 6b) in the $\sigma_{\theta \text {,max }}$ series in ES. Grey filled diamonds, open circles and black dots represent the LIW, WMDW and NACW fractions, respectively. (b) Same as (a) for the common period of observations. Symbols have the same meaning as in (a); solid grey and black lines represent fractions of LIW and WMDW, respectively, in CS. Dashed line is the fraction of NACW in this site, which is almost null.

Low frequency variability of this plume has been sporadically observed [Ambar et al., 2002, Díaz del Río, 2006] although a satisfactory explanation for the implications of this seasonality in the large scale circulation of the North Atlantic ocean is still lacking.

[22] A question that must be addressed is whether or not the seasonal variations of the hydrological properties and, hence, of the fractions of WMDW and LIW observed near the seafloor can be extrapolated to the whole Mediterranean water layer, which is thicker than $150 \mathrm{~m}$ in ES (Figure 5a). Obviously, the upper we move in this layer, the more mixed with the overlying NACW the Mediterranean water will be. The mixing takes place along lines like that indicated by the solid arrow in Figure 6b, which starts in the zone of Mediterranean water. The starting point will be closer to the point representing WMDW or LIW depending on the time of the year, which in turn would imply a similar ratio of WMDW/LIW proportions throughout the Mediterranean layer. In this likely situation and using Figure 7a, we could make a rough estimation of the amount of WMDW that flows out associated to the seasonal cycle. In absence of any seasonal signal, the fraction of WMDW in the outflow would be around 0.3 (Figure 7 ). The seasonal signal increases this fraction to around 0.5 during approximately half a year, implying an excess of WMDW volume drained out to the Atlantic ocean of $Q_{\text {out }} \times 0.2 \times 6 \mathrm{~Sv} \cdot \mathrm{month}$ which, if averaged over the whole year, would give an excess of $0.1 . Q_{\text {out }}$ or nearly $0.1 \mathrm{~Sv}$. This number is less than half the rate of formation of $0.3 \mathrm{~Sv}$ in the winter of 1992 reported by Send et al. [1995] from acoustic tomography observations, but it is of the same order of magnitude.

\subsection{Some Hints About Interannual Variability}

[23] Two-yearlong time series is insufficient to draw reliable conclusions about interannual variability. As far as the observed seasonal signal has its origin in the formation of deep water in the Gulf of Lions, a process with clear interannual variability [Mertens and Schott, 1998], this variability must be also important in the outflow through the Strait.

[24] In a recent study, Millot et al. [2006] present data of potential temperature and salinity collected in CS from January 2003 to April 2004 at $10 \mathrm{~m}$ above the seafloor, the same depth as the observations presented in this study. The series of lowest values of potential temperature shown in Figure 3 of Millot et al. [2006] suggest an annual cycle that reaches a minimum of hardly $13.0^{\circ} \mathrm{C}$ in middle-late summer of 2003. Actually, only few tens out of more than ten thousand observations in their study are below $13^{\circ} \mathrm{C}$, in contrast with the repeatedly observed $\theta<13^{\circ} \mathrm{C}$ in the data collected between February and May of 2006 in nearly the same location (more than $25 \%$ of the observations were below this value). Even when part of the discrepancies could have its origin in the slightly different position sampled in either experiment (Millot's data were obtained around $1 \mathrm{~km}$ north of the data showed here, at nearly the same depth) the facts that during 2005 and 2006 the absolute minimum of $\theta_{\min }$ was reached in April (Figure 4a) with values as low as $12.92^{\circ} \mathrm{C}$ (year 2006) while the lowest $\theta$ in March-April of years 2003 and 2004 were close to $13.1^{\circ} \mathrm{C}$ (Figure 3 of Millot et al. [2006]) and that the seasonal cycle of $\theta_{\text {min }}$ suggested by Millot's data has its minimum clearly shifted toward summer, make us to conclude that the differences reflect a clear interannual variability. If the sharp diminution of $\theta$ in early spring in Figure 4 echoes the formation of WMDW in the Gulf of Lions, the conclusion should be that this water was hardly formed in years 2003 and 2004, not at least dense enough to reach the bottom of the basin.

[25] Figure 8 shows the CRUTEM3v monthly anomalies of air temperature in this area between January 1950 and September 2006 and a zoom of the last nine years. They 


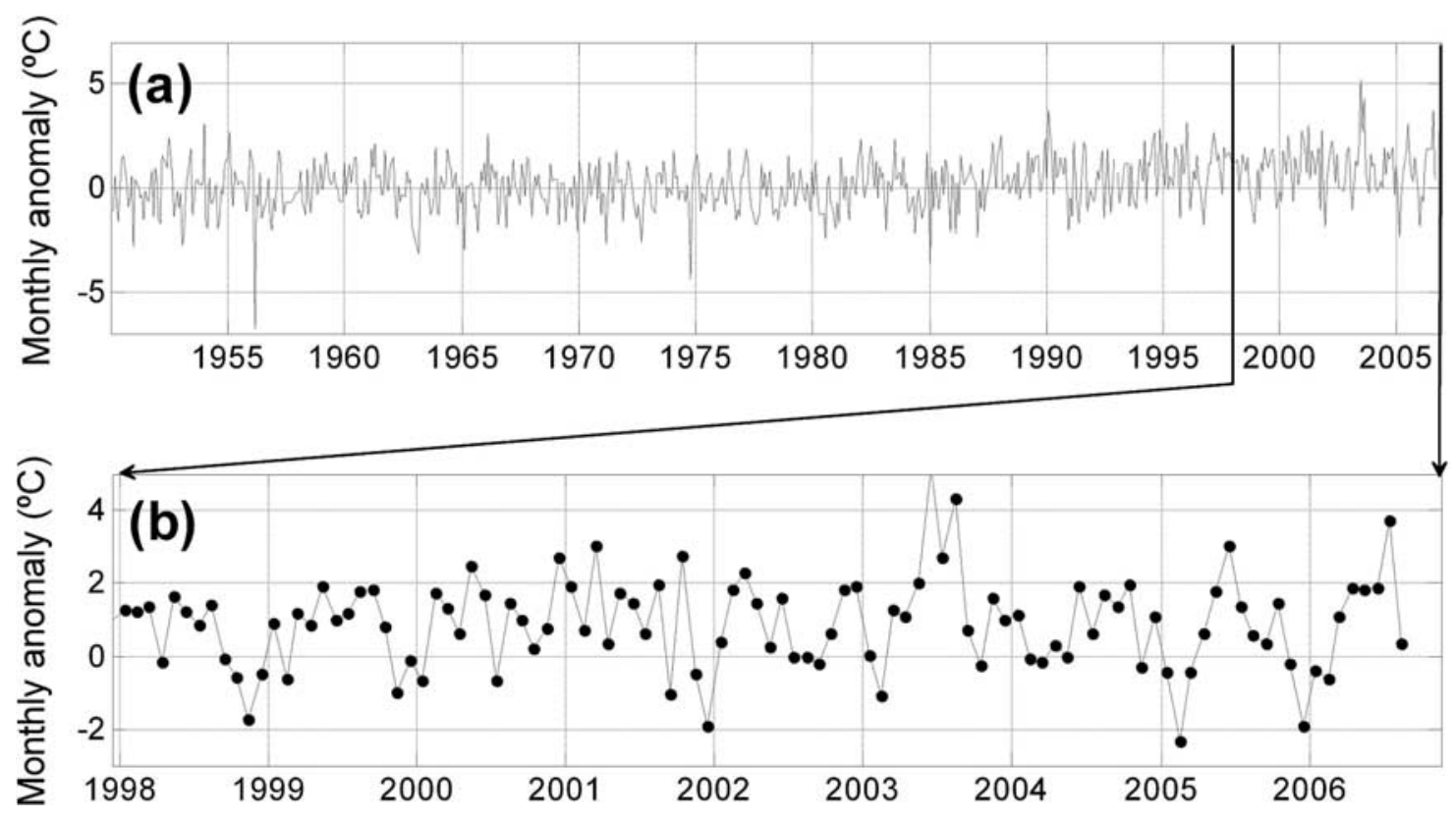

Figure 8. Monthly air temperature anomaly over the Gulf of Lions area from the CRUTEM3v database (University of East Anglia). (a) Anomaly since 1950 to 2006; (b) Detail of the period 1998-2006.

could be used as a proxy of the importance of the deep water convection. As expected, they show important interannual variability, which in turn will induce similar variability in the volume and characteristics of the WMDW formed each year. The large positive anomaly in summer 2003, the year of the heat wave over Europe that endured the highest summer temperatures of the past 500 years [Luterbacher et al., 2004; Ogi et al., 2005], was followed by a mild 2004 winter with the quite probable final result of a halting or a very limited production of deep water. On the contrary, winter 2005 (February) shows the greatest negative anomaly since 1985 and winter of 2006 is just as harsh, with important negative anomalies taking place earlier. Therefore these years gathered favorable winter climatic conditions to produce abundant WMDW, a fact already evidenced in recent regional studies for the 2004-2005 winter [López-Jurado et al., 2005; Schröder et al., 2006]. Figure $4 \mathrm{a}$ shows a quick decreases of $\theta_{\text {min }}$ in the outflow starting in early March 2005 and a much sharper diminution in late February 2006, which would be the consequence of the replenishment of the western Mediterranean basin with the newly formed water these years. Figure $8 \mathrm{~b}$ shows that year 2003 had a slight negative anomaly in late winter but a rather stable positive anomaly during early winter (November-December 2002), which would have hampered the preconditioning phase by limiting the buoyancy losses necessary for the deep convection in the late winter. Probably, the production of WMDW during this year was moderate and/or the water produced was lighter-thanaverage, thus suppressing the abrupt descent of $\theta$ in early spring [Millot et al., 2006, Figure 3].

[26] There are other open questions such as the reason that salinity series do not show an appreciable annual cycle or to what point the observations collected in the sills of Gibraltar can be used to quantify the amount of deep water formed each year. Some of these questions can be elucidated as the series being collected increase in length. In any case, the observations analyzed in this paper show the potential of simple monitoring stations deployed in key points of the Strait of Gibraltar in order to follow the undergoing changes in the Mediterranean basin at different timescales.

\section{Appendix A: Espartel Sill Versus Camarinal Sill Observations}

[27] Bray et al. [1995] showed that the greatest contrast between Atlantic and Mediterranean water is found in CS, which points at this sill as the best place for monitoring the exchange of water through the Strait by means of a unique station. However, ES is preferable for monitoring the outflow for several reasons. First, ES is the last topographic constriction for the Mediterranean outflow before it sinks in the North Atlantic until $1000 \mathrm{~m}$ depth where it becomes neutrally buoyant [Baringer and Price, 1997; Ambar et al., 2002]. Second, there are experimental [Farmer and Armi, 1988] and numerical [Castro et al., 2004; Sannino et al., 2004] results that suggest that ES holds permanent hydraulic control on the outflow regardless the strength of the fortnightly tidal cycle, a result that does not stand in the main CS, where the hydraulic control is flooded regularly almost every tidal cycle. Moreover, the fluctuations of the tidal currents and the depth of the interface in CS are positively correlated, which contributes noticeably to the mean exchange in a sort of tidally rectified flow [Bryden et al., 1994; Vargas et al., 2006]. The contribution is more important during spring tides when the flow exchange observed in CS is mainly due to this mechanism, likely related to the lost of the hydraulic control [Vargas et al., 2006]. This complicates the computation of low-frequency flows because they require the knowledge of the depth of the Mediterranean-Atlantic water interface at supra-tidal frequency, which is a rather elusive variable. On the 


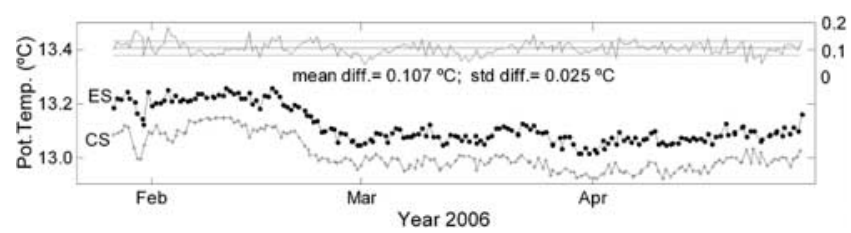

Figure A1. Time series of $\theta_{\min }$ in ES and CS from February to May 2006. The graph on top is the difference between both series (right scale) with the solid line indicating the mean value and the dashed lines marking the mean \pm one standard deviation.

contrary, the tidal rectification of flows is almost negligible in the Algeciras-Ceuta section at the eastern part of the Strait (see Figure 1 for location), where the low frequency exchange can be computed with reasonable accuracy using the low-passed (sub-tidal) time series of currents and the depth of the surface of null-velocity [Garcia Lafuente et al., 2000; Basheck et al., 2001; Vargas et al., 2006]. The result stems from the fact that, in this section, tidal currents in the upper Atlantic layer are not strong enough to reverse the subinertial inflow. A similar conclusion can be drawn for the Mediterranean layer in ES since neither tidal currents reverse the subinertial outflow [Farmer and Armi, 1988; see Figure 3]. Therefore the computation of the outflow from $\mathrm{ADCP}$ observations in ES is easier and, likely, more reliable than in CS.

[28] One question to be addressed is whether or not the observations collected in ES and CS provide the same information. Figure 3 shows differences between the original series in both sills but not in the time series of $\theta_{\min }$ and $\sigma_{\theta, \max }$ (Figure 4). This feature is better seen in Figure A1 that shows $\theta_{\min }$ series in ES and CS during the common period of observations. The series are very much alike (correlation coefficient 0.94 ) and maintain a rather constant difference $\left(0.107 \pm 0.021^{\circ} \mathrm{C}\right)$, indicating that the range of fluctuations is the same in both sills. The similitude is striking by the end of February 2006 when the sharp decrease of $\theta_{\min }$ is registered simultaneously and with the same scale of variation in both sills. In the case of $\sigma_{\theta, \max }$, the correlation coefficient diminishes $(r=0.70$, Figure not shown) and the difference is $0.089 \pm 0.018, \sigma_{\theta \text {, max }}$ in CS being higher than in ES. The similitude of $\theta_{\min }$ and $\sigma_{\theta, \max }$ series in both sites is encouraging and ensures that low frequency signals can be studied equally well using observations of either CS or ES.

\section{Appendix B: Tidal Flow and the $\sigma_{\theta, \max }$ Series}

[29] Another question to be analyzed refers to the time of the tidal cycle when $\sigma_{\theta, \max }$ is observed in CS. The question is relevant because the denser the water overflowing CS, the deeper it will come from the Mediterranean Sea and the stronger the Bernoulli suction in CS will be necessary. The required energy for the suction will be provided by tides, so that the timing of $\sigma_{\theta, \max }$ series must be closely bounded to the tidal cycle. The flow over CS can be either eastward or westward due to tides and the possibility that certain samples in the $\sigma_{\theta \text {, max }}$ series are flowing toward the Mediterranean sea cannot be rejected. Therefore it is important to check that the selected $\sigma_{\theta, \text { max }}$ samples correspond to instantaneous westward flow in order to ensure that the parcel has definitely left the Mediterranean Sea.

[30] Figure B1 confirms that at the time of $\sigma_{\theta, \max }$ the velocity is negative (westward), though it is not at its maximum. The histogram on the lower left corner indicates that water with $\sigma_{\theta, \max }$ is flowing out around two or three ours after the maximum outflow, a delay interpreted as the time it takes the less-mixed available Mediterranean water in the eastern side of the Strait to reach CS. In ES (Figure not shown) $\sigma_{\theta, \max }$ occurs slightly before the time of maximum outflow and the histogram is wider and flatter than in CS. It is interpreted as the result of the tidal dynamics in the Tangier basin, which is filled with Mediterranean water through CS during flood tide and drained out toward the Atlantic through ES during the whole tidal cycle and also toward the Mediterranean through CS during the next ebb tide. During this process, turbulent mixing in the basin erodes the peaks of $\sigma_{\theta, \max }$ observed in CS and homogenesis the outflow (compare the series in CS and ES during the common period presented in Figure 3), favoring the random spreading of extremes over the tidal cycle in the outflow through ES.

[31] The flow over CS is able to suction water residing at $700 \mathrm{~m}$ or more in the eastern side of the Strait [Stommel et al., 1973; Whitehead, 1985; see also Figure 2] where the Mediterranean water is less mixed and maintains purer $\theta / \mathrm{S}$ characteristics. Maximum suction will happen at the time of the maximum outflow and, from this time onwards, the water crossing the sill will exhibit purer and purer Mediterranean characteristics until the internal hydraulic jump formed downstream of CS during flood tide is realized [Farmer and Armi, 1988; Sannino et al., 2004] and triggers strong mixing. It happens around one hour before high tide



Figure B1. Scatterplot of potential density versus along strait velocity at $10 \mathrm{~m}$ above the seafloor in Camarinal sill. Small rectangles indicate the points with maximum potential density during each semidiurnal tidal cycle, which outcrop in the zone of negative (westward) velocity between -80 and $-160 \mathrm{~cm} \mathrm{~s}^{-1}$. The insert in the lower left is the histogram of the time difference between the occurrence of $\sigma_{\theta, \max }$ and the maximum outflowing velocity (hour 0 , dashed line), positive values meaning that $\sigma_{\theta, \max }$ occurs after the maximum. 
or, equivalently, 2 to $3 \mathrm{~h}$ after maximum outflow due to the standing wave nature of the barotropic tide in the Strait [García Lafuente et al., 1990]. The less mixed and, therefore, densest Mediterranean water is expected to be overflowing CS just before the internal bore reaches the sill, in good agreement with the observations (Figure B1). Once this water has crossed CS, it decelerates, mixes as it moves through the internal hydraulic jump and, finally, passes through ES where it is detected around 8 to $9 \mathrm{~h}$ later near the time of the maximum outflow of the next tidal cycle. Since ES is $20 \mathrm{~km}$ downstream of CS, the water parcel must move at an average speed of 0.6 or $0.7 \mathrm{~m} \mathrm{~s}^{-1}$ in the Tangier basin, which seems a reasonable value.

[32] Acknowledgments. The data analyzed in this work were collected within the frame of the Spanish-funded project INGRES (REN0301608/MAR). We acknowledge the Spanish Ministerio of Educación y Ciencia its financial support. ASR acknowledges a post-graduate fellowship from this Ministry. JCSG acknowledges a post-graduate fellowship from Consejería de Innovacion Ciencia y Empresa, Junta de Andalucía, Spain. We are grateful to the Climate Research Unit (CRU) of the University of East Anglia for the free use of its climatic database. We are also grateful to the crews of the R/Vs Odón de Buen and Francisco de Paula Navarro from the Instituto Español de Oceanografía for their help, assistance and welldone work during the deployment and recovering of the mooring lines in the often unfriendly environment of the Strait of Gibraltar. The ES monitoring station is part of the Mediterranean Sea monitoring network Hydro-Changes, sponsored by the CIESM.

\section{References}

Ambar, I., N. Serra, M. J. Brogueira, G. Cabeçadas, F. Abrantes, P. Freitas, C. Gonçalves, and N. Gonzalez (2002), Physical, chemical and sedimentological aspects of the Mediterranean outflow off Iberia, Deep Sea Res. II, 49, 4163-4177.

Baringer, M. O., and J. F. Price (1997), Mixing and spreading of the Mediterranean outflow, J. Phys. Oceanogr., 27, 1654-1677.

Basheck, B., U. Send, J. García Lafuente, and J. Candela (2001), Transport estimates in the Strait of Gibraltar with a tidal inverse model, J. Geophys. Res., 106, 31,033-31,044.

Béranger, K., L. Mortier, and M. Crépon (2005), Seasonal variability of the water transport through the Straits of Gibraltar, Sicily and Corsica, derived from a high-resolution model of the Mediterranean circulation, Prog. Oceanogr., 66, 341-364.

Bormans, M., C. Garrett, and K. R. Thompson (1986), Seasonal variability of the surface inflow through the Strait of Gibraltar, Oceanol. Acta, 9, $403-414$.

Bray, N. A., J. Ochoa, and T. H. Kinder (1995), The role of the interface in exchange through the Strait of Gibraltar, J. Geophys. Res., 100, 10,75510,776 .

Brohan, P., J. J. Kennedy, I. Haris, S. F. B. Tett, and P. D. Jones (2006), Uncertainty estimates in regional and global observed temperature changes: A new dataset from 1850, J. Geophys. Res., 111, D12106, doi:10.1029/2005JD006548.

Bruno, M., J. J. Alonso, A. Cózar, J. Vidal, A. Ruiz-Cañavate, F. Echevarría and J. Ruiz (2002), The boiling-water phenomena at Camarinal sill, the Strait of Gibraltar, Deep Sea Res. II, 49, 4097-4113.

Bryden, H. L., and T. H. Kinder (1991), Steady two-layer exchange through the Strait of Gibraltar, Deep Sea Res., 38(S1), S445-S463.

Bryden, H. L., J. Candela, and T. H. Kinder (1994), Exchange through the Strait of Gibraltar, Prog. Oceanogr., 33, 201-248.

Candela, J. (2001), Mediterranean water and global circulation, in Ocean Circulation and Climate, edited by G. Siedler, J. Church, and J. Gould, pp. 419-429, Academic Press, San Diego, Ca.

Candela, J., C. D. Winant, and H. L. Bryden (1989), Meteorologically forced subinertial flows through the Strait of Gibraltar, J. Geophys. Res., 94, 12,667-12,679.

Castro, M. J., J. A. García-Rodríguez, J. M. González-Vida, J. Macías, C. Parés, and M. E. Vázquez-Cendrón (2004), Numerical simulation of two-layer shallow water flows through channels with irregular geometry, J. Comput. Phys., 148, 497-526.

Díaz del Río, G. (2006), Patrones hidrológicos y variabilidad temporal de la circulación oceánica en la región plataforma/talud del Golfo Artabro, noroeste de Galicia, Ph.D. thesis, 187 p., Univ. of Vigo, Vigo, Spain.

Farmer, D., and L. Armi (1988), The flow of Mediterranean water through the Strait of Gibraltar, Prog. Oceanogr., 21, 1-106.
García, D., B. F. Chao, J. Del Río, I. Vigo, and J. García Lafuente (2006) On the steric and mass-induced contributions to the annual sea level variations in the Mediterranean Sea, J. Geophys. Res., 111, C09030, doi:10.1029/2005JC002956.

García Lafuente, J., J. L. Almazán, F. Fernández, A. Khribeche, and A. Hakimi (1990), Sea level in the Strait of Gibraltar: Tides, Int. Hydrogr Rev., LXVII(1), 111-130.

García Lafuente, J., J. M. Vargas, F. Plaza, T. Sarhan, J. Candela, and B. Baschek (2000), Tide at the eastern section of the Strait of Gibraltar, J. Geophys. Res., 105, 14,197-14,213.

García Lafuente, J., J. Delgado, J. M. Vargas, M. Vargas, F. Plaza, and T. Sarhan (2002a), Low-frequency variability of the exchanged flows through the Strait of Gibraltar during CANIGO, Deep Sea Res. II, 49, $4051-4067$.

García Lafuente, J., E. Alvarez Fanjul, J. M. Vargas, and A. W. Ratsimandresy (2002b), Subinertial variability in the flow through the Strait of Gibraltar, J. Geophys. Res., 107(C10), 3168, doi:10.1029/ 2001JC001104.

García Lafuente, J., J. Del Río, E. Alvarez-Fanjul, D. Gomis, and J. Delgado (2004), Some aspects of the seasonal variability around Spain, J. Geophys. Res., 109, C09008, doi:10.1029/2003JC002070.

Kinder, T. H., and H. L. Bryden (1990), Aspiration of deep waters through straits, in The Physical Oceanography of Sea Straits, edited by L. J. Pratt, pp. 295-319, Kluver Academic, Norwell, Mass.

Kinder, T. H., and G. Parrilla (1987), Yes, some of the Mediterranean outflow does come from great depth, J. Geophys. Res., 92(C3), 29012906

Lacombe, H., and C. Richez (1982), The regime of the Strait of Gibraltar, in Hydroynamics of Semi-enclosed Seas, edited by J. C. J. Nihoul, pp. 1374, Elsevier, Amsterdam.

López-Jurado, J. L., C. González-Pola, and P. Vélez-Belchí (2005), Observation of an abrupt disruption of the long-term warming trend at the Balearic Sea, western Mediterranean Sea, in summer 2005, Geophys. Res. Lett., 32, L24606, doi:10.1029/2005GL024430.

Luterbacher, J., D. Dietrich, E. Xoplaki, M. Grosjean, and H. Warner (2004), European seasonal and annual temperature variability, trends and extremes since 1500, Science, 303, 1499-1503.

MEDAR Group (2002), MEDATLAS/2002 database. Mediterranean and Black Sea database of temperature salinity and biochemical parameters, Climatological Atlas. IFREMER Edition.

MEDOC Group (1970), Observation of formation of deep water in the Mediterranean, Nature, 227, 1037-1040.

Mertens, C., and F. Schott (1998), Interannual variability of deep water formation in the Northwestern Mediterranean, J. Phys. Oceanogr., 28, $1410-1424$

Millot, C. (1999), Circulation in the western Mediterranean Sea, J. Mar. Sys., 20, 423-442.

Millot, C., J. Candela, J. L. Fuda, and Y. Tber (2006), Large warming and salinification of the Mediterranean outflow due to changes in its composition, Deep Sea Res. I, 53, 656-666.

Ogi, M., K. Yamazaki, and Y. Tachibana (2005), The summer northern annular mode and abnormal summer weather in 2003, Geophys. Res. Lett., 32, L04706, doi:10.1029/2004GL021528.

Parrilla, G., T. H. Kinder, and R. H. Preller (1986), Deep and intermediate Mediterranean water in the western Alborán Sea, Deep Sea Res. I, 33, 55-88.

Rayner, N. A., D. E. Parker, E. B. Horton, C. K. Folland, L. V. Alexander, D. P. Rowell, E. C. Kent, and A. Kaplan (2003), Globally complete analyses of sea surface temperature, sea ice and night marine air temperature, 1871-2000, J. Geophys. Res., 108(D14), 4407, doi:10.1029/ 2002JD002670.

Rayner, N. A., P. Brohan, D. E. Parker, C. K. Folland, J. J. Kennedy, M. Vanicek, T. Ansell, and S. F. B. Tett (2006), Improved analyses of changes and uncertainties in marine temperature measured in situ since the mid-nineteenth century: The HadSST2 dataset, J. Climate, 19, 446-469.

Sannino, G., A. Bargagli, and V. Artale (2002), Numerical modelling of the mean exchange through the Strait of Gibraltar, J. Geophys. Res., 107(C8), 3094, doi:10.1029/2001JC000929.

Sannino, G., A. Bargagli, and V. Artale (2004), Numerical modelling of the semidiurnal tidal exchange through the Strait of Gibraltar, J. Geophys. Res., 109, C05011, doi:10.1029/2003JC002057.

Schott, F., and K. D. Leaman (1991), Observations with moored acoustic Doppler current profilers in the convection regime in the Golfe du Lion, J. Phys. Oceanogr., 21, 558-574.

Schröder, K., G. P. Gasparini, M. Tangherlini, and M. Astraldi (2006), Deep and intermediate water in the western Mediterranean under the influence of the Eastern Mediterranean Transient, Geophys. Res. Lett., 33, L21607, doi:10.1029/2006GL027121. 
Send, U., F. Schott, F. Gaillard, and Y. Desaubies (1995), Observation of a deep convection regime with acoustic tomography, J. Geophys. Res., 100(C4), 6927-6941.

Stommel, H., H. Bryden, and P. Mangelsdorf (1973), Does some of the Mediterranean outflow come from great depth?, Pure Appl. Geophys., 105, 879-889.

Testor, P., and J. C. Gascard (2006), Post-convection spreading phase in the Northwestern Mediterranean Sea, Deep Sea Res. I, 53(5), 869-893, doi:10.1016/j.dsr.2006.02.004.

Vargas, J. M., J. García Lafuente, J. Candela, and A. J. Sánchez (2006), Fortnightly and monthly variability of the exchange through the Strait of Gibraltar, Prog. Oceanogr., 70(2-4), 466-485.

Wesson, J. C., and M. C. Gregg (1994), Mixing at Camarinal sill in the Strait of Gibraltar, J. Phys. Oceanogr., 21, 185-204.
Whitehead, J. A., Jr. (1985), A laboratory study of gyres and uplift near the Strait of Gibraltar, J. Geophys. Res., 90, 7045-7060.

G. Díaz del Río, Laboratorio Oceanográfico de A Coruña, Instituto Español de Oceanografía, A Coruña, Spain.

J. García Lafuente and A. Sánchez Román, Grupo de Oceanografía Física, Dpt. of Applied Physics II, ETSI Telecomunicación, Campus de Teatinos s/n, University of Málaga, E29071, Spain. (glafuente@ctima.uma.es)

J. C. Sánchez Garrido, Grupo de Puertos y Costas, University of Granada, Granada, Spain.

G. Sannino, Ocean Modeling Unit-Special Project Global ClimateENEA, C.R. Casaccia, Rome, Italy. 